\title{
Prevalence of Third Coronary Artery: Variation or Constant Coronary Artery?
}

\author{
Prevalencia de la Tercera Arteria Coronaria: ¿Variación o Arteria Coronaria Constante?
}

Dusica L. Maric ${ }^{1}$; Bojana Colic ${ }^{2}$; Milos Mirovic ${ }^{2}$; Mirela Eric ${ }^{1}$; Dragana Radosevic ${ }^{1}$; Nikola Knezi ${ }^{1}$ \& Dusan M. Maric ${ }^{3}$

MARIC, D. L.; COLIC, B.; MIROVIC, B.; ERIC, M.; RADOSEVIC, D.; KNEZI, N. \& MARIC, D. M. Prevalence of third coronary artery: Variation or constant coronary artery? Int. J. Morphol., 36 (4):1241-1245, 2018.

SUMMARY: Third coronary artery or supernumerary coronary artery is a direct branch from right aortic sinus and it supplies pulmonary conus and upper part of right ventricle. Third coronary artery is an important bridge for collateral circulation between right and left coronary system. The aim of this study was to determine the number of arteries that origin from right aortic sinus, their frequency and position. The study included 55 adult human hearts collected from Department of Anatomy. The hearts were morphologically studied by gross dissection for the prevalence and topographical anatomy of supernumerary coronary arteries. Out of 55 hearts, 26 (47.3 $\%)$ had one right coronary artery, $23(41.8 \%)$ had two right coronary arteries, and $6(10.9 \%)$ had three coronary arteries. The supernumerary arteries arises from the right aortic sinus. Right supernumerary coronary arteries may be present in about $52.7 \%$ of the Serbian population. Interpretation of signs and symptoms of coronary occlusion should therefore consider possible contribution of this blood vessels.

KEY WORDS: Supernumerary coronary artery; Third coronary artery; Right coronary artery.

\section{INTRODUCTION}

The arterial supply of heart is provided by right and left coronary arteries. The levels and number of coronary ostia are occasionally variable. Variation of coronary artery is usually related to the length, branches quantity, origin and irrigated territories (Ballesteros et al., 2011).

The high incidence of supernumerary arteries on right is in marked contrast to the rare occurrence of accessory vessels to left coronary artery system (Schlesinger et al., 1949).

Conus artery is the first branch of right coronary artery (RCA). Immediately after its origin, it ramifies anteriorly on the lowest part of pulmonary conus and upper part of right ventricle. When conus artery arises independently from the anterior aortic sinus it is called as third coronary artery (TCA) (Schlesinger et al.; Udayasankari \& Jain, 2014). It is also known as preinfundibular or right Vieussens's artery, adipose or accessory artery, and supernumerary coronary artery (Schlesinger et al.; Lujinovic et al., 2008). Fourth coronary artery (FCA) can be present when two conus arteries, each with independent aortic origin, are present (Fiss, 2007).
Although its distribution is relatively unexplored, TCA may supply variable parts of the anterior wall of the right ventricle and the interventricular septum (Sahni \& Jit, 1990; Ben-Gal et al., 1997; von Lüdinghausen \& Ohmachi, 2001).

The reported prevalence of the TCA ranges from 33 to $51 \%$ with evidence of age and ethnic variability (Schlesinger et al.; Miyazaki \& Kato, 1988; Stankovic \& Jesic, 2004; Standring, 2016).

Various authors have suggested that TCA provides a collateral connection between the right and left coronary arteries, and the anastomosis is known in the literature as Vieussens ring which is formed around the pulmonary trunk. This ring represents a significant path of collateral circulation under conditions of coronary insufficiency (Sankari et al., 2011).

Understanding variations of coronary artery is important in the diagnosis of unexplained clinical signs and symptoms as well as surgical procedures.

TCA may be a benefit for the person having it (Sankari et al.). Collateral circulation is a key factor in the

\footnotetext{
${ }^{1}$ Department of Anatomy, Faculty of Medicine, University of Novi Sad, Serbia.

${ }^{2}$ Faculty of Medicine, University of Novi Sad, Serbia.

${ }^{3}$ Department of Surgery, Faculty of Medicine, University of Novi Sad, Serbia.
} 
pathophysiology of coronary artery disease. Symptoms and prognosis among patients with advanced coronary artery disease depend largely on the degree of collateral circulation (Gouda et al., 2009).

This study was undertaken with the purpose of estimating the number of arteries that origin from right aortic sinus, their frequency and position.

\section{MATERIAL AND METHOD}

The study was carried out in 55 formalin fixed normal adult human hearts obtained from the collection of Department of Anatomy, Faculty of Medicine, University of Novi Sad, Serbia. Specimens with observable cardiac defects or congenital anomalies were excluded from the study. Approval from the Institutional Ethics committee was taken for the study.

The hearts were dissected to prove the origins of right supernumerary coronary arteries. With the aid of dissecting lenses, the branches of the supernumerary coronary artery were displayed and traced distally to confirm the course, branching and termination. Next the aorta was longitudinally opened at the level of right posterior aortic sinus to enable the visualization and analysis of coronary ostia. The most representative specimens were photographed with the camera "Olympus" (18x optical zoom). We analyzed the macroscopic appearance, location and relationship of right

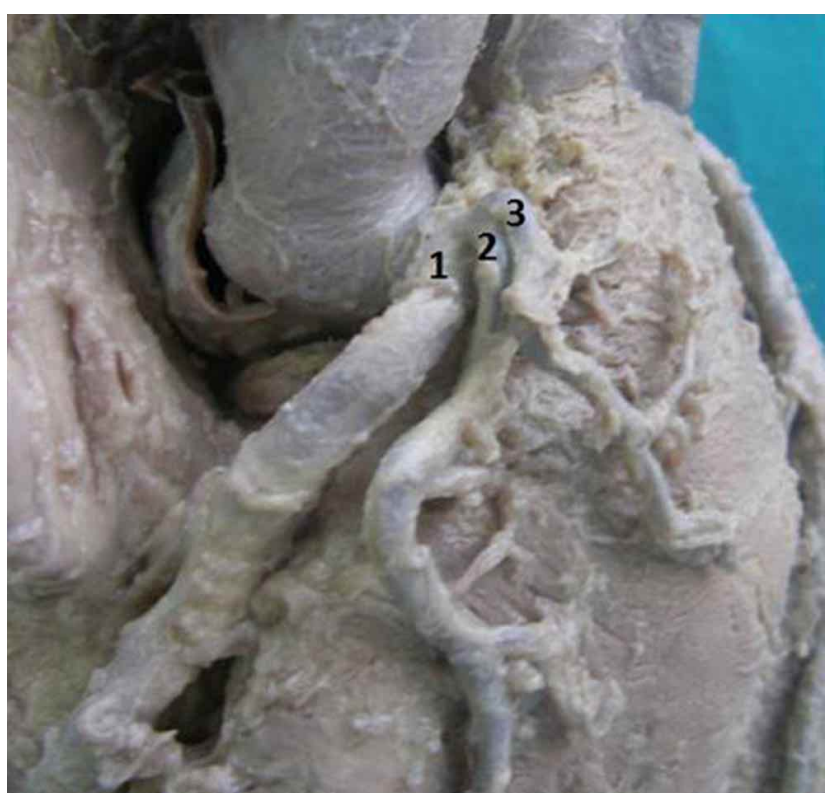

Fig. 1. Human heart (dissection preparation). 1. Right coronary artery 2 . Third coronary artery 3 . Fourth coronary artery. coronary artery with supernumerary arteries and divided them into basic groups. The external diameters at the starting points of these branches were measured using $0.01 \mathrm{~mm}$ sensitive digital calipers. To determine the dominant circulation, the artery that supplies the posterior interventricular sulcus was investigated.

The incidence of supernumerary coronary artery and type of arterial vascularization of the heart is statistically analyzed.

\section{RESULTS}

Out of 55 dissected hearts, $26(47.3 \%)$ had one right coronary artery, $23(41.8 \%)$ had two coronary arteries, and $6(10.9 \%)$ had three coronary arteries.

The supernumerary arteries arises from the right anterior aortic sinus, close to the origin of RCA (Fig. 1).

The TCA was present in 23 hearts (41.8\%) (Fig. 2). The orifice, in all cases, was in front of and right from the orifice of RCA. Radius of the orifice of TCA was 1-2 mm, and its distance from the orifice of RCA was 1.5-4.5 mm. In all cases TCA supply conus arteriosus, anterior wall of the right ventricle, interventricular septum and the apex of the heart. TCA was found to arise independently from the anterior aortic sinus. TCA had subepicardial course without any myocardial bridges and noticeable anastomosis, and distance

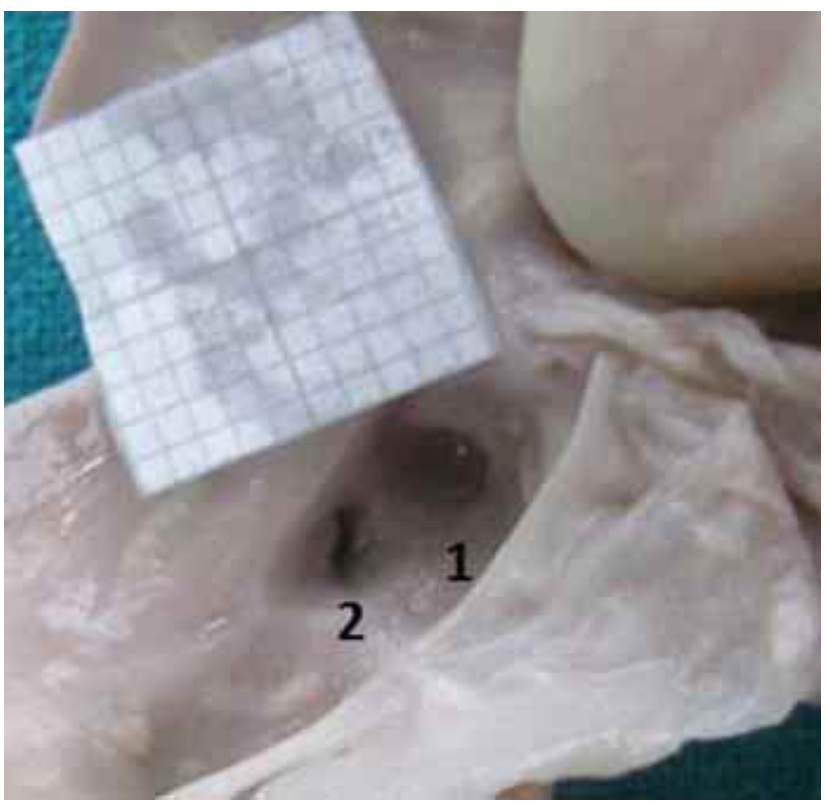

Fig. 2. Human heart (dissection preparation)

1. Orifice of right coronary artery 2 . Orifice of third coronary artery. 
from the orifice of RCA was $1.5-4.5 \mathrm{~mm}$. In these hearts ostium of TCA was located at the same level and to the left of the ostium of RCA.

FCA was present in 6 hearts $(10.9 \%)$ (Fig. 3). These 6 hearts showed 3 ostia in anterior aortic sinus (for RCA, TCA and FCA). Ostium of FCA was located at the same level and right of the ostium of TCA. FCA originated from separate right aortic sinus with orifice radius from 0.5 to 0.8 $\mathrm{mm}$, and distance from the orifice of RCA was $2.5-4.5 \mathrm{~mm}$. All these FCA were short, single vessels which supplied the pulmonary cone.

We found that at 54 of hearts $(93.33 \%)$ was represented the right type of arterial vascularization while only 1 heart $(6.67 \%)$ was represented the left type.

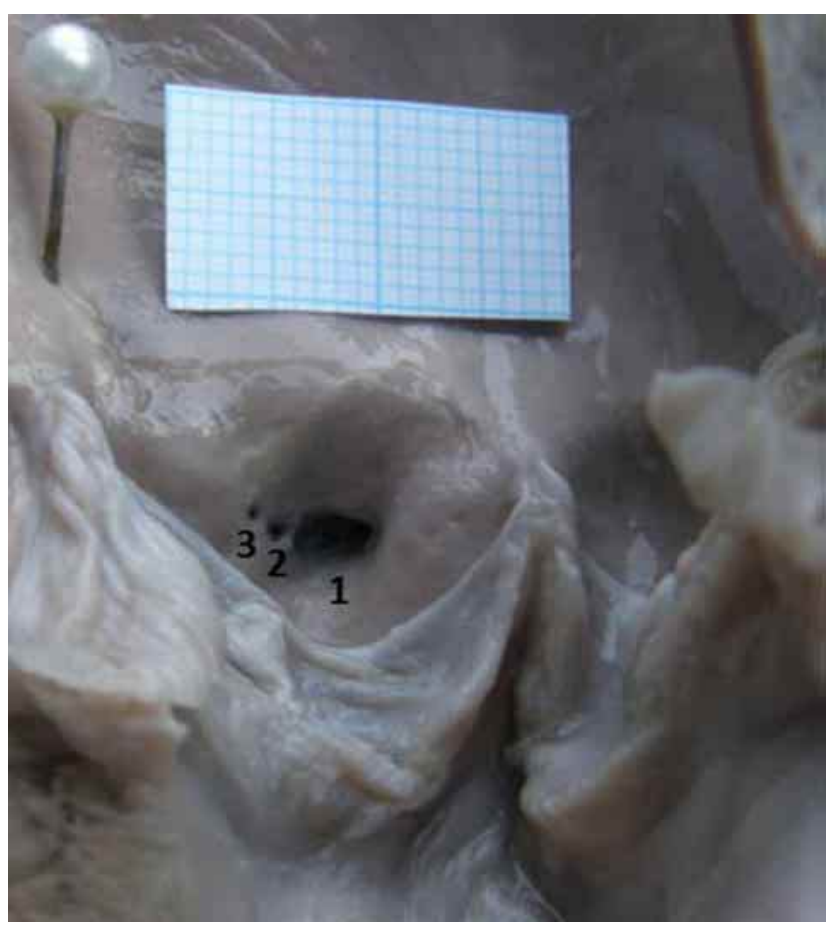

Fig. 3. Human heart (dissection preparation). 1. Orifice of right coronary artery 2 . Orifice of third coronary artery 3 . Orifice of fourth coronary artery.

\section{DISCUSSION}

Morphological analysis of 55 hearts has revealed a prevalence of $47.3 \%$ of RCA, $41.8 \%$ of TCA, while FCA is the rarest artery $(10.9 \%)$. Other dissection studies have reported various incidence which are shown in Table I.

These findings suggest ethnic variability and appear to support the suggestion by Garg et al. (2000) that there are
Table I. Prevalence of the TCA and FCA in various populations.

\begin{tabular}{llrc}
\hline Author & Population & \multicolumn{1}{c}{ TCA } & FCA \\
\hline Kurjia et al. (1986) & Iraqi & $8 \%$ & - \\
Miyazaki \& Kato (1988) & Japanese & $36.8 \%$ & - \\
Wolloschek et al. (2001) & Germans & $60 \%$ & - \\
Saidi et al. (2002) & Kenyan & $17 \%$ & $2 \%$ \\
Kalpana (2003) & Indians & $24 \%$ & - \\
Stankovic \& Jesic (2004) & Serbian & $34.8 \%$ & - \\
Lujinovic et al. (2008) & Bosnian & $32 \%$ & $4 \%$ \\
Fazliogullari et al. (2010) & Turks & $68 \%$ & - \\
Sankari et al. (2011) & Indians & $16.67 \%$ & $6.66 \%$ \\
Present study (2018) & Serbian & $41.8 \%$ & $10.9 \%$ \\
\hline
\end{tabular}

geographical differences in coronary artery variations, which may have a genetic background. Ballesteros et al. and Apsara (2014) results did not prove any statistically relation between the prevalence of TCA and sex.

Different methodologies used for the study may also contribute to the observed variations. Coronary angiograms frequently are unsuccessful to visualize TCA (Jyothi Lakshmi et al., 2017) or FCA.

Earlier embryologists confirmed that coronary arteries developed by angiogenesis (i.e. growing from aortic root). The recent studies have shown that the coronary arteries develop from a complex capillary network derived from epicardial mesenchyme. The significant positive correlation between the lengths of RCA with the fetal age indicated that there are significant changes in the development of the coronary vasculature with fetal heart development. The separate orifices for TCA and RCA had been explained by inadequate unification of these two vessels, during their growth towards the ascending aorta (Reese et al., 2002; Singh et al., 2017). Olabu et al. (2007) noticed three types of origin of TCA depending on the number of orifices (common orifice with the RCA, single orifice separate from that of the RCA, and two orifices).

Since the right conus artery did not arise from the RCA always, the study of level of ostium gains importance for angiographic dye injection. The ostium of TCA may be to the left of and superior to the ostium of RCA as reported by Stankovic \& Jesic. According to Apsara the most common position of TCA ostium is at the same level and to the left of the ostium of RCA. In the study of Sankari et al. the level of ostia below the level at sinotubular junction was $73.34 \%$.

One question that could be asked today is: What is normal incidence of RCA or TCA? The area of perfusion of the TCA is variable and may be more extensive than usual 
in some individuals. About $10 \%$ of clinical malpractice is due to the ignorance of the anatomical variations (Ajayi et al., 2013). The size of the coronary arteries typically determines the treatment options in the management of coronary artery disease as small arteries may cause anastomotic difficulties during bypass grafting and can influence the outcome in procedures such as stenting and balloon angioplasty. The possibility of large TCA and myocardial bridges over it should be thought of during various surgical procedures to avoid damage.

We can conclude based on our results, that supernumerary right coronary artery is not rare as previously thought. More than $52.7 \%$ of heart in our sample had supernumerary coronary artery. Detecting the number of supernumerary coronary arteries, quantity and place of opening the aortic sinus on the findings of coronary angiography, as well as correct interpretation, certainly affect the preoperative preparation and the type of cardiac intervention.

Medicolegal importance of TCA was pointed out by Gouda et al. as it might help in establishment of partial identity of an individual if ante mortem record of third coronary artery was available. Since this study is based on an autopsy, more researches on the third coronary artery are needed in living individuals.

\section{CONCLUSIONS}

Morphological analysis of 55 hearts showed that the front of the right aortic sinus usually leaves only the right coronary artery $(47.3 \%)$, followed by a third coronary artery $(41.8 \%)$, while the least represented the fourth coronary arteries $(10.9 \%)$. More than $52.7 \%$ of the heart has a right supernumerary coronary artery. TCA and FCA is commonly located at the same level and to the left of the ostium of RCA. We noticed right type of arterial vascularization at 93.33\% and left type at $6.67 \%$ in hearts that have TCA and FCA. Knowledge of individual and racial variations in coronary arteries is essential for the diagnosis and treatment of coronary artery patients.

MARIC, D. L.; COLIC, B.; MIROVIC, M.; ERIC, M.; RADOSEVIC, D.; KNEZI, N. \& MARIC, D. M. Prevalencia de la tercera arteria coronaria: ¿Variación o arteria coronaria constante?. Int. J.Morphol., 36(4):1241-1245, 2018.

RESUMEN: La tercera arteria coronaria o arteria coronaria supernumeraria es una rama directa del seno aórtico derecho y su- ministra el cono pulmonar y la parte superior del ventrículo derecho. La tercera arteria coronaria es importante para la circulación colateral entre el sistema coronario derecho e izquierdo. El objetivo de este estudio fue determinar el número de arterias de origen del seno aórtico derecho, su frecuencia y posición. El estudio incluyó 55 corazones humanos adultos pertenecientes al Departamento de Anatomía. Los corazones se estudiaron morfológicamente mediante disección macroscópica para determinar la prevalencia y la anatomía topográfica de las arterias coronarias supernumerarias. De 55 corazones, $26(47,3 \%)$ tenían una arteria coronaria derecha, $23(41,8 \%)$ tenían dos arterias coronarias derechas, y 6 $(10,9 \%)$ tenían tres arterias coronarias. Las arterias supernumerarias surgen del seno aórtico derecho. Las arterias coronarias supernumerarias derechas pueden estar presentes en aproximadamente el 52,7 \% de la población serbia. La interpretación de los signos y síntomas de la oclusión coronaria debería considerar la posible contribución de estos vasos sanguíneos.

PALABRAS CLAVE: Arteria coronaria supernumeraria; Tercera arteria coronaria; Arteria coronaria derecha.

\section{REFERENCES}

Ajayi, N. O.; Lazarus, L.; Vanker, E. A. \& Satyapal, K. S. Anatomic parameters of the left coronary artery: an angiographic study in a South African population. Int. J. Morphol., 31(4):1393-8, 2013.

Apsara, M. P. The third coronary artery: lessons revisited. J. Evol. Med. Dent. Sci., 3(43):10704-10, 2014.

Ballesteros, L. E.; Ramirez, L. M. \& Quintero, I. D. Right coronary artery anatomy: anatomical and morphometric analysis. Rev. Bras. Cir. Cardiovasc., 26(2):230-7, 2011.

Ben-Gal, T.; Sclarovsky, S.; Herz, I.; Strasberg, B.; Zlotikamien, B.; Sulkes, J.; Birnbaum, Y.; Wagner, G. S. \& Sagie, A. Importance of the conal branch of the right coronary artery in patients with acute anterior wall myocardial infarction: electrocardiographic and angiographic correlation. J. Am. Coll. Cardiol., 29(3):506-11, 1997.

Fazliogullari, Z.; Karabulut, A. K.; Unver Dogan, N. \& Uysal, I. I. Coronary artery variations and median artery in Turkish cadaver hearts. Singapore Med. J., 51(10):775-80, 2010.

Fiss, D. M. Normal coronary anatomy and anatomic variations. Appl. Radiol., 36(1):14-26, 2007.

Garg, N.; Tewari, S.; Kapoor, A.; Gupta, D. K. \& Sinha, N. Primary congenital anomalies of the coronary arteries: a coronary: arteriographic study. Int. J. Cardiol., 74(1):39-46, 2000.

Gouda, H. S.; Mestri, S. C. \& Aramani, S. C. Third coronary artery - Boon or Bane? J. Indian Acad. Forensic Med., 31(1):62-4, 2009.

Jyothi Lakshmi, G. L.; Vineesh, V. \& Dini, M. Third coronary artery: a cadaveric study. Int. J. Anat. Res., 5(1):3410-4, 2017.

Kalpana, R. A study on principal branches of coronary arteries in humans. J. Anat. Soc. India, 52(2):137-40, 2003.

Kurjia, H. Z.; Chaudhry, M. S. \& Olson, T. R. Coronary artery variation in a native Iraqi population. Cathet. Cardiovasc. Diagn., 12(6):386-90, 1986.

Lujinovic, A.: Ovcina, F. \& Tursic, A. Third coronary artery. Bosn. J. Basic Med. Sci., 8(3):226-9, 2008.

Miyazaki, M. \& Kato, M. Third coronary artery: its development and function. Acta Cardiol., 43(4):449-57, 1988.

Olabu, B. O.; Saidi, H. S.; Hassanali, J. \& Ogengo, J. A. Prevalence and distribution of the third coronary artery in Kenyans. Int. J. Morphol., 25(4):851-4, 2007. 
Reese, D. E.; Mikawa, T. \& Bader, D. M. Development of the coronary vessel system. Circ. Res., 91(9):761-8, 2002.

Sahni, D. \& Jit, I. Blood supply of the human interventricular septum in north-west Indians. Indian Heart J., 42(3):161-9, 1990.

Saidi, H. S.; Olumbe, A. O. \& Kalebi, A. Anatomy and pathology of coronary artery in adult black Kenyans. East Afr. Med. J., 79(6):323-7, 2002.

Sankari, T. U.; Kumar, J. V. \& Saraswathi, P. The anatomy of right conus artery and its clinical significance. Recent Res. Sci. Technol., 3(10):30$9,2011$.

Schlesinger, M. J.; Zoll, P. M. \& Wessler, S. The conus artery; a third coronary artery. Am. Heart J., 38(6):823-36, 1949.

Singh, S.; Ajayi, N.; Lazarus, L. \& Satyapal, K. S. Morphologic relationship between the coronary arteries during fetaldevelopment. Int. J. Morphol., 35(4):1197-202, 2017.

Standring, S. Gray's Anatomy. The Anatomical Basis of Clinical Practice. $41^{\text {st }}$ ed. New York, Elsevier, 2016.

Stankovic', I. \& Jesic, M. Morphometric characteristics of the conal coronary artery. McGill J. Med., 8:2-6, 2004.

Udayasankari, T. \& Jain, M. L. Arteria Coni Arteriosi - pattern of origin with clinical and embryological interpretation in south Indian population. SIRJ-HMS, 1(1):47-54, 2014.

von Lüdinghausen, M. \& Ohmachi, N. Right superior septal artery with "normal" right coronary and ectopic "early" aortic origin: a contribution to the vascular supply of the interventricular septum of the human heart. Clin. Anat., 14(5):312-9, 2001.

Wolloschek, T.; Zipfel, J. \& Konerding, M. A. Aortic valve structures as landmarks for determining coronary artery ostia in transthoracic echocardiography. Herz, 26(7):461-7, 2001.
Corresponding author:

Assoc. Prof. Dusica L. Maric MD PhD

Department of Anatomy

Faculty of Medicine

University of Novi Sad

SERBIA Email: dusica.maric@mf.uns.ac.rs
maricduska@gmail.com

Received: 15-05-2018

Accepted: 06-08-2018 